\title{
3 Research Square

\section{Adolescent physical activity: the role of parental social support and the level of physical activity. Social Support and Physical Activity of Parents and Adolescents.}

Edina Maria de Camargo ( $\nabla$ edinacamargo@gmail.com )

Universidade Federal do Parana https://orcid.org/0000-0003-2127-2606

Jose Francisco López-Gil

Universidade de Murcia

Thiago Silva Piola

Universidade Federal do Parana

Jorge Augusto Pinto Silva Mota

Universidade do Porto Faculdade de Desporto

Wagner de Campos

Universidade Federal do Paraná

Research article

Keywords: motor activity, parents, adolescents, social support

Posted Date: March 27th, 2020

DOI: https://doi.org/10.21203/rs.2.16556/v2

License: (c) (1) This work is licensed under a Creative Commons Attribution 4.0 International License.

Read Full License 


\section{Abstract}

Background: Maximising the level of physical activity in adolescents has been a concern for many researchers given the benefits provided by physical activity.

Aim: To verify the relationship between the level of moderate vigorous physical activity (MVPA) of parents or legal guardians and that of social support (SS) with the level of MVPA in adolescents.

Methods: Cross-sectional study that selected 1390 (59.6\% female) adolescents. The questionnaires IPAQ, QAFA and ASAFA were used.

Results: In relation to boys, receiving incentives from parents who "assist always" (OR=1.96 $\mathrm{Cl} 95 \%=1.16-3.32)$ and having parents/legal guardians who meet the MVPA recommendations $(\mathrm{OR}=2.78$ - $\mathrm{Cl} 95 \%=1.76-4.38)$ was associated with meeting the MVPA recommendations. The probability increases when adjusted by socioeconomic status ( $\mathrm{OR}=3.47-\mathrm{Cl} 95 \%=1.73-6.96)$ or education level $(\mathrm{OR}=4.20-\mathrm{Cl} 95 \%=1.96-9.02)$. Regarding girls, parents who "encourage sometimes" was associated negatively $(\mathrm{OR}=0.61-\mathrm{Cl} 95 \%=0.37-0.98)$ and meet the MVPA recommendations $(\mathrm{OR}=2.04-$ $\mathrm{Cl} 95 \%=1.46-2.87)$ was associated positively with meeting the recommendations for adolescents. The likelihood raises when adjusted by socioeconomic status $(\mathrm{OR}=2.11-\mathrm{Cl} 95 \%=1.36-3.29)$ or education level $(\mathrm{OR}=4.30-\mathrm{Cl} 95 \%=2.41-7.69)$.

Conclusions: Having parents who meet with the physical activity recommendations demonstrated higher results in adolescents engaging 60 minutes of MVPA daily when compared to receiving social support, for both boys and girls.

\section{Background}

The increase in the prevalence of physical inactivity, both in developed and developing countries, is of great concern since it is the fourth leading cause of death in the world, besides increasing the risk of suffering from 35 chronic diseases $^{1,2}$. It is estimated that, on average, every fourth one in the world population is not active enough ${ }^{3}$. Therefore, if current trends continue, the WHO (World Health Organization) goal of achieving an insufficient $10 \%$ relative reduction in physical activity (PA) in the population by 2025 will not be achieved ${ }^{4,5}$.

Following the WHO recommendations, adolescents (13 to 18 years old) should perform a minimum of 60 minutes/day of moderate vigorous physical activity (MVPA) in order to benefit their health ${ }^{6}$. In the case of adults, it is indicated to practise 150 minutes a week of moderate physical activity (MPA) or 75 minutes of vigorous physical activity (VPA) .

In Brazilian adolescents, physical inactivity in free time reaches $54.3 \%{ }^{7}$. The factors that can influence these data are very varied, including sociodemographic, economic or social/family support indicators, among others ${ }^{8-16}$. 
In this sense, numerous national and international studies indicate that the level of social support (SS) in the family context, as well as in the peer group, is linked to higher levels of PA in adolescents ${ }^{17-19}$. In addition, the fact that parents practise PA at the same time is a good model for children to get involved in $\mathrm{PA}^{20-23}$. A longitudinal study that included 13.000 students observed that PA engaged by parents showed an association with that engaged by their children ${ }^{23}$.

However, to date, the studies have presented the association of the PA level of parents or legal guardians and SS in isolation ${ }^{20-23}$. The present study seeks to investigate the chance that an adolescent has to comply with the MVPA recommendations if parents or legal guardians also comply with it and, in parallel, it investigates the SS received from parents or legal guardians to practise PA (encourage, practise together, transport, assist and comment on how well the adolescent is doing his/her PA). Once investigated, this gap can contribute to a better understanding of how to maximise the levels of MVPA in adolescents, with the support and example coming from parents (father, mother, caregiver).

Thus, the aim of this study was to verify the relationship between the level of MVPA of parents or legal guardians and that of SS with the level of MVPA in adolescents.

\section{Methods}

The study followed the standards of research involving human beings of the National Health Council (resolution number 466/2012), having been approved by the Research Ethics Committee of the Federal University of Paraná (CAAE: 98133218.8.0000.0102) and authorised by adolescents' the parents or legal guardians by means of a free and informed consent form.

This is a cross-sectional study conducted in 2018 with a representative sample of adolescents aged 15 to 17 enrolled in a public high school.

For the preliminary sample calculation, an association of $\mathrm{OR}=1.49$ was considered between $\mathrm{SS}$ and $\mathrm{PA}^{24}$, a prevalence of being insufficiently active of $50 \%{ }^{25}$, a confidence level of $95 \%(a=0.05)$ with a power of $80 \%(\beta=0.20)$, resulting in a minimum sample of 804 subjects. However, an increase of $30 \%$ was considered for possible losses and refusals, which estimated a minimum sample required for the study of 965 subjects. The sample was selected from the process of sampling by multiple stages, conglomerates, in three stages: 1st stage - all state schools were stratified according to each of the nine administrative regions of the city of Curitiba; 2 nd stage - two schools were drawn in each regional; 3rd stage - a simple random selection of a class of each year was performed, according to the number of students, separated by sex, required for a given region. Finally, all students in each class were invited to participate in the study.

A total of 2506 adolescents were evaluated. Those who presented physical and/or cognitive limitations (informed by the school) $(n=12)$ and were 18 years old $(n=125)$ were exempt. We also excluded the adolescents who did not present the informed consent form $(n=104)$, those who refused to participate in 
the study, or missed the day of collection $(n=56)$, as well as those who answered the questionnaires incorrectly or did not answer about PA level $(n=819)$. Thus, the analytical sample of the study was 1390 adolescents.

Statistical analyses carried out subsequently showed that this sample could identify statistically significant ratios above 1.36 and below 0.73 , considering a power of $80 \%(\beta=20 \%)$, a confidence level of $95 \%(a=5 \%)$ and considering a prevalence of $34 \%$ of adolescents with low SS and who did not meet the minimum recommendations for PA.

\section{Physical Activity - Parents / Legal Guardians and Adolescents}

The moderate vigorous physical activity (MVPA) level of parents or legal guardians was measured through the IPAQ questionnaire - short version (International Physical Activity Questionnaire), in which parents or legal guardians reported "how many days a week" and "how long a day" they practised MVPA, over a normal week ${ }^{26}$. The time dedicated to each physical activity (PA) practice (leisure and displacement) per week was categorised according to the current recommendations of MVPA practice ("it meets the recommendations" $\geq 150$ minutes per week of MVPA practice and "it does not meet" $(<150$ minutes per week of MVPA practice) ${ }^{6}$.

The PA level of adolescents was evaluated by the Physical Activity Questionnaire for Adolescents $(\text { QAFA })^{27}$. This questionnaire was first developed in the checklist format by Sallis et al, $1996^{28}$ for North American adolescents, translated and adapted for Brazilian adolescents by Farias-Júnior et al, $2012^{27}$. The questionnaire consists of a list of 24 types of MVPAs, with the possibility of adolescents adding activities beyond those listed. In Brazilian adolescents, the questionnaire showed good reproducibility $\left(\mathrm{CCl}=0.88 ; \mathrm{Cl}_{95 \%}=0.84-0.91\right)$ and concurrent validity when compared to 24 -hour recall $(r=0.62 ; p<0.001)^{27}$. To analyse the MVPA level, it was classified as "it meets the recommendations" ( $\geq 60$ minutes per day of MVPA practice) and "it does not meet" ( $<60$ minutes per day of MVPA practice), to consider the recommendation by the WHO is that adolescents (13 to 18 years old) perform at least 60 minutes/day of MVPA to obtain health benefits ${ }^{6}$.

Social Support received from parents or legal guardians for the practice of Physical Activity.

The social support (SS) of the adolescents' parents or legal guardians to practise PA (physical activity) was measured by the scale of 5 items Social Support for Physical Activity Practice for Adolescents (ASAFA), which has satisfactory consistency (SS of parents $a \geq 0.77$ and IFC $\geq 0.83)^{29}$. Adolescents reported the frequency (never $=1$, rarely $=2$, frequently $=3$, always $=4$ ) with which parents offered some type of SS for the practice of PA (encourage, practise, transport, assist, comment) during a typical or normal week ${ }^{29}$, through the questions: "How often do your parents encourage you to practise PA? Do they practise PA with you? Do they transport you or provide transportation so that you can go to the place where you practise PA? Do they assist you in PA? Do they comment that you are doing your PA well?" For purposes of analysis, and with the aim of ensuring comparability with similar studies ${ }^{30}$, the response 
options "rarely" and "frequently" were grouped and classified as "sometimes". Thus, the weekly frequency categories of SS were classified as never, sometimes and always.

\section{Sociodemographic Information and Health}

Sex was self-reported ("male", "female") and age was calculated from the date of birth (informed by the adolescent) subtracted from the date of data collection and divided by 365 , resulting in: "15 years", "16 years", "17 years".

The nutritional status was calculated by the Body Mass Index (BMI), from the measured data of body mass and height $(\mathrm{kg} /$ height). The evaluation of the body mass was carried out by a trained researcher using a portable digital anthropometric scale (W721, Wiso, Brazil) with resolution of 100 grams and capacity of 150 kilograms $(\mathrm{Kg})$. The adolescents were barefoot, wearing only light clothing and were guided to maintain their anatomical position, to position themselves with their backs to the scale and to distribute their body mass equally between both feet. A portable stadiometer (W721, Wiso, Brazil) was used to measure the total height of the participants. The participants were in the anatomical position with the head positioned in the Frankfurt Plan and, at the time of measurement, they performed an inspiratory apnea. Two measurements were performed and in case of divergences of more than 0.1 centimetres $(\mathrm{cm})$ between measurements the procedure was performed again ${ }^{31}$. The technical error of measurement was obtained by carrying out a number of repeated measurements on the same subject, either by the same observer, taking the differences and entering them into an appropriate equation. For intra-observer TEM of the two measurements taken it was used the following equation: , where " $D$ " is the difference between measurements and " $\mathrm{N}$ " is the number of individuals measured ${ }^{32}$. Likewise, intraclass correlation coefficient (ICC) was calculated to verify the reliability of the measurements, giving a result of 0.96 .

The identification of nutritional status was carried out through the classifications of BMI Z scores for each sex and age proposed by the WHO, being: Low weight $=<-2$ SD (standard deviation), Eutrophic = $\geq-2 S D$ and $<+1 D P$, Overweight $=\geq+1$ SD and $<+2$ DP and Obesity $=\geq+2$ SD, classified as "not overweight" and "overweight" ${ }^{33}$. The education level of the main family breadwinner and his/her socioeconomic status (SES) were evaluated with a standardised questionnaire ${ }^{34}$. The Education level was classified as: Elementary School, Secondary School or higher Education levels. SES was classified into three categories: "low" (class C+D), "medium" (class B1+B2) and "high" (class A1+A2) (ABEP, 2016) ${ }^{34}$.

\section{Collectingdata}

Parents and/or legal guardians received the questionnaire at home to answer it. The parents'/legal guardians' questionnaire was sent out by the adolescents together with the terms of consent for the adolescents to agree to. Adolescents who had parental permission to participate in the survey answered the questionnaire at school during physical education classes with the help of the researchers who applied the questionnaire.

\section{Data Analysis}


After having identified the data distribution by the Kolmogorov-Smirnov test, descriptive statistics were used to distribute absolute and relative frequencies. The chi-square test $\left(\chi^{2}\right)$ was used to verify differences in proportions in relation to sex and recommended levels of MVPA in adolescents. Pearson's chi-square test was used to compare proportions between genders, then a post hoc test was used to demonstrate which categories showed the greatest difference.

Binary logistic regression was used to test the relationship among the study variables (between the level of MVPA of parents or legal guardians and that of SS with the level of MVPA in adolescents). By the enter criterion, the value of $p \leq 0.20$ for the entry of the variable in the adjusted model was adopted. Afterwards, the interaction for age, nutritional status, main breadwinner's education level and socioeconomic status (SES) logistic regression analysis models were introduced (multiplication of the possible moderating variable with the independent variable - example: age * SS: practice). In all, 20 interactions were tested (age, nutritional status, main breadwinner's education level and SES with the SS scale and MVPA parentes - significant values were presented in tables 2 and 3 )

To avoid bias related to the complex sample selection process (cluster stratification), the association analyses were corrected by the complex design using the SPSS software version 23.0 "complex sample" command. This procedure was used to ensure that the estimates reflect the population data of the elementary units in the sample.

\section{Results}

The sample was composed by 1390 adolescents (59.6\% female) and their respective parents/ legal guardians. Table 1 show the variables of the study stratified by sex, where: nutritional status $(p=0.001)$, SES $(p=0.015)$ and the level of MVPA of parents $(p=0.021)$ showed significant differences (Table 1$)$.

In relation to boys, receiving incentives from parents who "assist always" (OR=1.96 - Cl95\%=1.16-3.32) and having parents/legal guardians who meet the MVPA recommendations (OR=2.78 - Cl95\%=1.764.38) was associated with meeting the MVPA recommendations. The chances of boys meeting 60 minutes of MVPA daily increases by almost $3 x$ when parents meet the recommendation of MVPA and have a high socioeconomic status $(\mathrm{OR}=3.47-\mathrm{Cl} 95 \%=1.73-6.96)$. It increases by almost $4 \mathrm{x}$ when parents comply with the MVPA recommendation and have a high level of education $(\mathrm{OR}=4.20-\mathrm{Cl} 95 \%=$ 1.96-9.02) (Table 2).

Regarding girls, parents who "encourage sometimes" (OR=0.61 $-\mathrm{Cl} 95 \%=0.37-0.98)$ and meet the MVPA recommendations $(\mathrm{OR}=2.04-\mathrm{Cl} 95 \%=1.46-2.87)$ was associated with meeting the recommendations for adolescents. The chances of girls meeting 60 minutes of MVPA daily increases when their parents meet the MVPA recommendation and have a high socioeconomic status $(\mathrm{OR}=2.11-\mathrm{Cl} 95 \%=1.36-3.29)$. It increases by almost $4 \mathrm{x}$ when parents comply with the MVPA recommendation and have a high level of education $(\mathrm{OR}=4.30-\mathrm{Cl} 95 \%=2.41-7.69)($ Table 3$)$.

Table 1, 2, 3. 


\section{Discussion}

Numerous studies indicate that the level of SS in the family context, as well as recommended levels of PA (physical activity) from parents or legal guardians are linked to higher levels of PA in adolescents ${ }^{16-23,35}$. However, scientific literature has analysed these variables independently. Aiming at this, the present study sought to investigate the variables in the same sample of adolescents, in order to analyse how much the fact of having parents or legal guardians physically active and receiving their support for the practice of PA could contribute to achieve the recommendations of Moderate Vigorous Physical Activity (MVPA) in adolescents.

\section{Boys}

In the present study, for boys, the support of parents related to assist and the fact of having parents who meet the MVPA recommendations were associated with meeting recommended MVPA levels. A systematic review ${ }^{35}$ published in 2010 consistently observed that adolescents who received greater Social Support (SS) reported higher levels of PA, reinforcing the importance of this support in adolescent (boys and girls) participation in $\mathrm{PA}^{35}$. However, the low number of studies made it impossible to analyse the association among different types of SS, PA intensities and adolescent characteristics, such as sex and age $^{35}$.

In the study by Prado et $\mathrm{al}^{30}$, the fact of always receiving positive reinforcement from parents was associated with boys PA. In the same way, there are other studies that show encouragement as a way of SS most commonly reported by adolescents, regardless of their source ${ }^{35-38}$. Most of the SS types explored in this study did not present a significant association with the practice of PA. This finding was observed as well in the multivariate analyses by Fermino et $\mathrm{al}^{24}$, Prado et $\mathrm{al}^{30}$ and Piola et $\mathrm{al}^{36}$, who also did not observe significant associations between most types of SS and PA.

In this sense, Duncan et al ${ }^{37}$ observed that older adolescents have greater perception from family members when this comes in the form of encouragement and talk about PA. Similarly, Yao and Rhodes ${ }^{22}$ also noted that parental encouragement was the SS most strongly related to their children's PA.

Parental SS for adolescents to engage PA is a crucial factor, however, the scientific literature has reported a greater emphasis on social support from friends than that provided from families, for older adolescents, according to a systematic review performed by Mendonça and colleagues $(2014)^{38}$. Nevertheless, having active parents (i.e., parents who comply with PA recommendations) as role models, seems to have a positive influence even with older adolescents, as indicate the results of our study. Thus, in this age phase, adolescents may not give as much relevance to the SS of parents, but they may give as much importance to the example they offer about PA practice ${ }^{38}$. 
In a systematic review ${ }^{39}$ of studies that examined both children's and parents' PA, conducted in countries with high development index (United States, United Kingdom, Australia, Canada, France and Portugal) all with cross-sectional design, it was showed that fathers' MVPA was associated with that MVPA of children, as well as the participation in vigorous activities of children was associated with the practice of VPA (vigorous physical activity) of parents ${ }^{39}$. For mothers, the practice of MPA (moderate physical activity) was associated with the practice of MPA that of children ${ }^{39}$. Both associations were confirmed for weekdays and weekends ${ }^{39}$.

The physical activities reported by parents in their childhood and adolescence were also associated with higher levels of PA among adolescents ${ }^{40}$. Adolescents with physically active parents in the past and currently, were six times $\left(\mathrm{OR}=6.670-\mathrm{Cl}_{95 \%}=1.940-2.790\right)$ more likely to be physically active compared to adolescents whose parents/legal guardians were not physically active in the past ${ }^{40}$. Therefore, it seems necessary to understand these parental constructions that measured PA since childhood ${ }^{39,40}$.

\section{Girls}

In the case of girls, the fact of receiving incentives from parents (encourage) and having parents/legal guardians who comply with the MVPA recommendations was associated with complying the MVPA recommendations, encourage was associated negatively and comply with the MVPA recommendations positively. Piola et $\mathrm{al}^{36}$, in the city of Curitiba (Brazil), in a study of adolescents found that the fact that parents "always" commented positively on the activities was absolutely associated with the practice of $\mathrm{PA}$ in post-pubertal adolescents (girls and boys) $\left(\mathrm{OR}=2.60-\mathrm{Cl}_{95 \%}=1.01-6.71\right)$. Variations in associations between different types and sources of SS can also be observed according to the age and sex of adolescents ${ }^{19,38,41}$. As in the study of Prado et $\mathrm{al}^{30}$, where having parents who "practise" PA together with their daughters was positively associated with the practice of PA (five or more days in the week of 60 minutes of MVPA) for girls. Some studies show that SS from friends seems to be more associated with meeting the PA recommendation in older adolescents ${ }^{38}$. In this sense, encouraging girls to practise PA could be an important tool, coming from parents and family members, to maximise levels of PA. This is due to the fact that an increased SS contributes to raise the level of PA in adolescents ${ }^{19}$.

Complying with the MVPA recommendations established for parents contributes to increasing the chance of adolescent girls complying with the MVPA recommendation by almost twice as much. Bound together, these findings demonstrate that the regular practice of parents' PA, combined with the support they provide to their children for, this purpose, are important factors not only for adolescents in PA, but also for the practice of MVPA. When close people are present and value their behaviour, adolescents' self-esteem tends to rise; thus, it increases their perception of self-efficacy ${ }^{21}$; what can contribute, inexorably, to higher levels of $\mathrm{PA}^{21}$. Parental or legal guardian encouragement can have a direct influence on the active 
participation of adolescents, since it can lead adolescents to participate in a more automatic process, establishing routines.

The results confirm the importance of the family environment for adolescent's PA $19,22,35,38,39$. It indicates that the influence of the family environment (receiving support from parents or legal guardians and having active parents or legal guardians) in the dynamic behaviour of adolescents, operates, in a way, through the attitudes they receive from parents or legal guardians, such as support and especially the example of being physically active ${ }^{23,41}$. In the present study, having parents who meet with the PA recommendations demonstrated higher results in adolescents engaging 60 minutes of PA day when compared to receiving SS, for both boys and girls. Nevertheless, more studies are needed to confirm the influence of the parents' example about the meeting of the PA recommendations for adolescents.

At the same time, more studies that investigate the interaction of parental education level and SES are required, since this study has shown that education level and SES increase the possibilities of boys and girls engaging 60 minutes of MVPA, if the main family breadwinner has both high education level and SES. The authors suggest that families with parents with high education level may have more knowledge about the benefits of PA and thus engage more PA and encourage their children. Notwithstanding, on the basis of the results of Global Matrix report, a significant low negative correlation was observed between the overall PA and some sociodemographic indicators (e. g. Human Development Index and the growth national income per capita $)^{42}$. For this reason, developing effective strategies to offer PA opportunities for all should be a national public health prime concern in all countries despite the SES.

\section{Limitations}

Some points should be considered when interpreting the results of this study. One of them is reverse causality, a common characteristic in studies with a cross-sectional design, which does not allow investigating a cause and effect relationship or determining the direction of the relationships. However, this design has been used in several studies like this. The study was developed in a single Brazilian city and has typical characteristics of well-developed urban centres, which does not allow extrapolating the findings to rural centres and other cities in the country.

The sample only consisted of adolescent students from public schools making it impossible to extrapolate the results to higher classes. However, the representative sample and statistical analyses ensure an interpretation of the data for large populations of public schools, an important point in the field of interventions related to public and preventive health.

The use of reported measures depends on the accuracy and recall power of the respondent's responses. In an attempt to minimise this bias, researchers were trained to assist adolescents in answering questionnaires. The instrument used to measure physical activity does not allow the identification of all domains and contexts in which the activities were practised. For this reason, obtaining a more accurate 
measure would contribute to reducing type 1 error. However, as it is a large study, with a representative sample, the use of questionnaires proved to be the best alternative.

\section{Conclusion}

In the present study, having parents who meet with the PA recommendations demonstrated higher results in adolescents engaging 60 minutes of MVPA daily when compared to receiving SS, for both boys and girls. In particular, regarding girls and aiming that one of the big problems related to physical inactivity is to make girls more physically active, the results of this study contribute to warn about the importance of having parents who meet with the recommendation of PA. The repeated encouragement and forms of support from parents/legal guardians, in addition to the example of being physically active, can initiate and build confidence so that the perceived behavioural control is improved and becomes a routine in the adolescents' lifestyle.

\section{Abbreviations}

ASAFA=Social Support for Physical Activity Practice for Adolescents

BMI=Body Mass Index

IPAQ=International Physical Activity Questionnaire

MPA=Moderate Physical Activity

MVPA= Moderate Vigorous Physical Activity

PA=Physical Activity

QAFA=Physical Activity Questionnaire for Adolescents

SES=Socioeconomic Status

SS=Social Support

VPA=Vigorous Physical Activity

WHO $=$ World Health Organization

\section{Declarations}

Ethics approval and consent to participate (attached statements) - The study followed the standards of research involving human beings of the National Health Council (resolution number 466/2012), having been approved by the Research Ethics Committee of the Federal University of Paraná (CAAE: 
98133218.8.0000.0102) and authorised by adolescents' the parents or legal guardians by means of a free and informed consent form. Consent was requested in writing.

Consent for publication - Not Applicable.

Availability of data and material - The datasets generated and/or analysed during the current study are not publicly available, the data are part of a doctoral thesis, which will be defended in February 2020. But are available from the corresponding author on reasonable request. The authors declare that all data supporting the findings of this study are available within the article.

Competing interests - The authors declare that they have no competing interests.

Funding - EMC - This work was supported by the Coordination of Improvement of Higher Education Personnel - Brazil (CAPES). Research grant in the PhD program in physical education at UFPR (Federal University of Paraná). - Financing Code 001. JAPSM - It was supported by grants: FCT: SFRH / BSAB / 142983/2018 and UID / DTP / 00617/2019 as well as the Santander Universities 2018 Scholarship Program. Research scholarship in the master's and doctoral program in physical education at the University of Porto.

Authors' contributions - EMC, Responsible for all aspects of the work. JFLG and TSP, Writing the manuscript. JAPSM and WC, Relevant critical content review. All authors read and approved the final manuscript.

Acknowledgements. - Not Applicable.

\section{References}

1. Guthold R. Stevens GA, Riley LM, Bull FC. Global trends in insufficient physical activity among adolescents: a pooled analysis of 298 population-based surveys with 1.6 million participants. Lancet Glob Health. 2020;S2352-4642(19)30323-2.

2. Booth FW, Roberts CK, Thyfault JP, Ruegsegger GN, Toedebusch RG. Role of Inactivity in Chronic Diseases: Evolutionary Insight and Pathophysiological Mechanisms. Physiol Revi. 2017;97(4):1351-402. 
3. Guthold R, Stevens GA, Riley LM, Bull FC. Worldwide trends in insufficient physical activity from 2001 to 2016: a pooled analysis of 358 population-based surveys with 1.9 million participants. Lancet Glob Health. 2018;6(10):e1077-1086.

4. Sallis JF, Bull F, Guthold R, et al. Progress in physical activity over the Olympic quadrennium. Lancet. 2016;388(10051):1325-36.

5. World Health Organization. Global action plan on physical activity 2018-2030: more active people for a healthier world. Genova: WHO. 2018.

6. World Health Organization. Global recommendations on physical activity for health. Genova: WHO, 2010.

7. Cureau FV, Silva TLN, Bloch KV et al. ERICA: Leisure-time physical inactivity in Brazilian adolescents. Rev Saúde Públ.2016;50(1):1-11.

8. Ding D, Lawson KD, Kolbe-Alexander TL et al. The economic burden of physical inactivity: a global analysis of major non-communicable diseases. Lancet. 2016;388(10051):1311-1324.

9. Lear SA, Hu W, Rangarajan S et al. The effect of physical activity on mortality and cardiovascular disease in 130000 people from 17 high-income, middle-income, and low-income countries: the PURE study. Lancet. 2017;390(10113):2643-54.

10. Lee IM, Shiroma EJ, Lobelo F, Puska P, Blair SN, Katzmarzyk PT. Effect of physical inactivity on major non-communicable diseases worldwide: an analysis of burden of disease and life expectancy. Lancet. 2012;380(9838):219-229.

11. Ortega FB, Ruiz JR, Castillo MJ, Sjöström M. Physical fitness in childhood and adolescence: a powerful marker of health. Int J Obes. 2008;32(1):1-11.

12. Skrede T, Steene-Johannessen J, Anderssen SA, Resaland GK, Ekelund U. The prospective association between objectively measured sedentary time, moderate-to-vigorous physical activity and cardiometabolic risk factors in youth: a systematic review and meta-analysis: Physical activity and metabolic health. Obes Rev. 2019;20(1):55-74.

13. Tarp J, Child A, White T, et al. Physical activity intensity, bout-duration, and cardiometabolic risk markers in children and adolescents. Int J Obes. 2018;42(9):1639-50.

14. Garcia JM, Sirard JR, Deutsch NL, Weltman A. The influence of friends and psychosocial factors on physical activity and 447 screen time behavior in adolescents: a mixed-methods analysis. J Behav Med. 2016;39:610-23.

15. Bauman AE, Reis RS, Sallis JF, Wells JC, Loos RJ, Martin BW. Correlates of physical activity: why are some people physically active and others not? Lancet. 2012;380(9838):258-71. 
16. Salvy SJ, Haye K, Bowker JC, Hermans RC. Influence of peersand friends on children's and adolescents' eating and activitybehaviors. Physicol Behav. 2012;106:369-78.

17. Van der horst K, Paw MJ, Twisk JW, Van Mechelen W. A brief review on correlates of physical activity and sedentariness in youth. Med Sci Sports Exerc. 2007;39(8):1241-50.

18. Raudsepp L. The relationship between socio-economic status,parental support and adolescent physical activity. Acta Paediatr. 2006;95:93-8.

19. Laird Y, Fawkner S, Kelly P, McNamee L, Niven A. The role of 450 social support on physical activity behaviour in adolescent girls: a systematic review and meta-analysis. Int J Behav Nutr Phys Act. 2016;13:79.

20. Sallis J, Taylor WC, Dowda M, Freedson PS, Pate RR. Correlates of vigorous physical activity for children in grades 1 through 12: comparing parent-reported and objectively measured physical activity. Ped Exer Sci. 2002;14(1):30-44.

21. Cheng LA, Mendonça G, Farias Júnior JC. Physical activity in adolescents: analysis of the social influence of parents and friends. J Pediatr. 2014;90(1):35-41.

22. Yao CA, Rhodes RE. Parental correlates in child and adolescent physical activity: a meta-analysis. Int J Behav Nutr Phys Act. 2015;12:10.

23. Ornelas IJ, Perreira KM, Ayala GX. Parental influences on adolescent physical activity: a longitudinal study. Int J Behav Nutr Phys Act. 2007;4:3.

24. Fermino RC, Rech CR, Hino AA, Rodriguez Anez CR, Reis RS. Physical activity and associated factors in highschool adolescents in Southern Brazil. Rev Saude Publ. 2010;44(6):986-95.

25. Barbosa Filho VC, Campos W, Bozza R, Lopes AS. The prevalence and correlates of behavioral risk factors for cardiovascular health among Southern Brazil adolescents: a cross-sectional study. BMC Pediatrics. 2012;12:130.

26. Matsudo et al. Questionário internacional de atividade física (IPAQ): Estudo de validade e reprodutibilidade no Brasil. Rev Bras de Ativ Fís Saúde. 2001v. 6, n. 1.

27. Farias Júnior JC de, Lopes A da S, Mota J, Santos MP, Ribeiro JC, Hallal PC. Validade e reprodutibilidade de um questionário para medida de atividade física em adolescentes: uma adaptação do Self-Administered Physical Activity Checklist. Rev Bras Epidemiol. 2012;15(1):198-210.

28. Sallis JF, Strilmiller P k, Harsha DW, et al. Validation of interviewer-and self- administered physical activity checklists for fifth grade students. Off J Am Coll Sport Med. 1996;28:840-851. 
29. Farias Júnior JC, Mendonça G, Florindo AA, Barros MVG. Reliability and validity of a physical activity social support assessment scale in adolescents - ASAFA Scale. Rev bras epidemiol. 2014;17(2):355-370.

30. Prado CV, Lima AV, Fermino RC, Rodriguez-Anez CR, Reis RS. Social support and physical activity in adolescents from public schools: the importance of family and friends. Cad Saúde Pública. 2014;30:82738 .

31. Tritschler, K. Medida e avaliação em educação física e esportes de Barrow \&amp; McGEE. Barueri-SP, 2003.

32. Ulijaszek SJ, Kerr DA. Anthropometric measurement error and the assessment of nutritional status. $\mathrm{Br}$ J Nutr. 1999 Sep;82(3):165-77.

33. World Health Organization. WHO child growth standards: length/height for age, weight-for-age, weight-for-length, weight-for-height and body mass index-for-age, methods and development: WHO; 2006.

34. Associação Brasileira de Empresas de Pesquisa. Critério de Classificação Econômica São Paulo, Brasil: ABEP; 2016.

35. Beets MW, Cardinal BJ, Alderman BL. Parental social support and the physical sctivity-related behaviors of youth: a review. Health Educ Behav. 2010;37:621-44.

36. Piola TS, Bacil EDA, lumi PW, Camargo EC et al. Sexual Maturation, social support and physical activity in adolescents. Cuadernos De Psicología Del Deporte. 2019;19(3):125-138.

37. Duncan SC, Duncan TE, Strycker LA. Sources and types of social support in youth physical activity. Health psychology: official journal of the Division of Health Psychology. Health Psychol. 2005;24(1):3-10.

38. Mendonça G, Cheng LA, Melo EN, Farias Junior JC. Physical activity and social support in adolescents: a systematic review. Health Educ Res. 2014;29:822-39

39. Neshteruk CD, Nezami BT, Nino-Tapias G, Davison KK, Ward DS. The influence of fathers on children's physical activity: A review of the literature from 2009 to 2015. Prev Med. 2017;102:12-19.

40. Christofaro DGD, Andersen LB, Andrade SM, et al. Adolescents' physical activity is associated with previous and current physical activity practice by their parents. $J$ Pediatr. 2018;94(1): 48-55.

41. Timperio AF, Van Stralen MM, Brug J, Bere E, et al. Direct and indirect associations between the family physical activity environment and sports participation among 10-12 year-old European children: testing the EnRG framework in the ENERGY project. Int J Behav Nutr Phys Act. 2013;10:15.

42. Aubert et al. Global Matrix 3.0 Physical activity report card grades for children and Youth: results and analysis from 49 countries. JPAH. 2018; 15(Suppl 2), S251-S273. 
Tables

Table 1. Sociodemographic information and health, social support and data on physical activity stratified by $\operatorname{sex}(n=1390)$.

\begin{tabular}{|c|c|c|c|c|c|c|c|c|}
\hline \multirow{2}{*}{\multicolumn{2}{|c|}{ Sociodemographic Information and Health }} & \multicolumn{2}{|c|}{ Boys } & \multicolumn{2}{|c|}{ Girls } & \multirow[b]{2}{*}{$p$} & \multicolumn{2}{|c|}{ TOTAL } \\
\hline & & $\mathrm{n}$ & $\%$ & $\mathrm{n}$ & $\%$ & & $\mathrm{n}$ & $\%$ \\
\hline \multirow[t]{3}{*}{ Age } & 15 & 175 & 37.7 & 289 & 62.3 & 0.090 & 464 & 33.4 \\
\hline & 16 & 203 & 40.5 & 298 & 59.5 & & 501 & 36.0 \\
\hline & 17 & 184 & 43.3 & 241 & 56.7 & & 425 & 30.6 \\
\hline \multirow[t]{2}{*}{ Nutritional Status } & Not Excess of Weight & 469 & 38.8 & 741 & 61.2 & $0.001^{*}$ & 1210 & 87.1 \\
\hline & Excess of Weight & 93 & 51.7 & 87 & 48.3 & & 180 & 12.9 \\
\hline \multirow[t]{3}{*}{ The main breadwinner's education level } & Elementary School & 217 & 40.3 & 322 & 59.7 & & 539 & 38.8 \\
\hline & Secondary School & 192 & 38.8 & 303 & 61.2 & 0.490 & 495 & 36.6 \\
\hline & Higher Education levels & 153 & 43.0 & 203 & 57.0 & & 356 & 25.6 \\
\hline \multirow[t]{3}{*}{ SES } & Low SES & $93^{a}$ & 35.8 & $167^{a}$ & 64.2 & & 260 & 18.7 \\
\hline & Medium SES & $348^{a}$ & 40.1 & $520^{a}$ & 59.9 & $0.015 \square$ & 868 & 62.4 \\
\hline & High SES & $121^{\mathrm{a}}$ & 46.2 & $141^{b}$ & 53.8 & & 262 & 18.8 \\
\hline \multicolumn{2}{|c|}{ 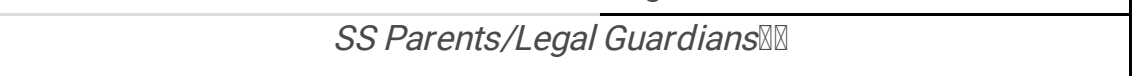 } & $\mathrm{n}$ & $\%$ & $\bar{n}$ & $\%$ & $p$ & $\mathrm{n}$ & $\%$ \\
\hline \multirow[t]{3}{*}{ Encourage } & Never & 104 & 37.5 & 173 & 62.5 & & 277 & 19.9 \\
\hline & Sometimes & 313 & 40.3 & 463 & 59.7 & 0.168 & 776 & 55.8 \\
\hline & Always & 145 & 43.0 & 192 & 57.0 & & 337 & 24.2 \\
\hline \multirow[t]{3}{*}{ Practice together } & Never & 205 & 37.4 & 343 & 62.6 & & 548 & 39.4 \\
\hline & Sometimes & 288 & 42.0 & 398 & 58.0 & 0.060 & 686 & 49.4 \\
\hline & Always & 69 & 44.2 & 87 & 55.8 & & 156 & 11.2 \\
\hline \multirow[t]{3}{*}{ Transport } & Never & 268 & 40.5 & 394 & 59.5 & & 662 & 47.6 \\
\hline & Sometimes & 176 & 40.1 & 263 & 59.9 & 0.955 & 439 & 31.6 \\
\hline & Always & 118 & 40.8 & 171 & 59.2 & & 289 & 20.8 \\
\hline \multirow[t]{3}{*}{ Assist } & Never & 239 & 39.4 & 367 & 60.6 & & 606 & 43.6 \\
\hline & Sometimes & 235 & 40.4 & 346 & 59.6 & 0.355 & 581 & 41.8 \\
\hline & Always & 88 & 43.3 & 115 & 56.7 & & 203 & 14.6 \\
\hline \multirow[t]{3}{*}{ Comment } & Never & 209 & 38.7 & 331 & 61.3 & & 540 & 38.8 \\
\hline & Sometimes & 232 & 43.9 & 296 & 56.1 & 0.992 & 528 & 38.0 \\
\hline & Always & 121 & 37.6 & 201 & 62.4 & & 322 & 23.2 \\
\hline \multicolumn{2}{|c|}{ Level of MVPA** } & $\mathrm{n}$ & $\%$ & $\mathrm{n}$ & $\%$ & $p$ & $\mathrm{n}$ & \\
\hline \multirow[t]{2}{*}{ Parents/Legal Guardians } & It does not meet & 411 & 42.5 & 557 & 57.5 & $0.021^{*}$ & 968 & 69.6 \\
\hline & It meets (150 minutes/week) & 151 & 35.8 & 271 & 64.2 & & 422 & 30.4 \\
\hline \multirow[t]{2}{*}{ Adolescents } & It does not meet & 367 & 65.3 & 564 & 68.1 & 0.296 & 931 & 67.0 \\
\hline & It meets (60 minutes/day) & 195 & 34.7 & 264 & 31.9 & & 459 & 33.0 \\
\hline
\end{tabular}

SES: socioeconomic status; SS: Social Support; MVPA: moderate vigorous physical activity;

$a, b$ each letter of subscript indicates a subset of gender (male and female) categories whose column proportions do not differ significantly from each other, Bonferroni's post hoc; 
*Statistically significant for the chi-square test for continuity correction; $₫$ Statistically significant for the linear association by chisquare test; $\mathrm{p}<0.05$. ${ }^{\star *}$ Meets physical activity recommendation $(\mathrm{WHO}, 2010)^{6}$

$\mathbb{Q S S}$ Parents/Legal Guardians: How often do your parents encourage you to practice PA (physical activity)? Do they practice PA with you? Do they transport you or provide transportation so that you can go to the place where you practice PA? Do they assist you in PA? Do they comment that you are doing your PA well?

Table 2. Association the social support and the level of physical activity of parents/legal guardians with regards to recommended MVPA levels in adolescent boys ( $n=1390)$.

\begin{tabular}{|c|c|c|c|c|c|c|c|c|c|c|c|c|c|c|c|}
\hline \multirow{3}{*}{\multicolumn{2}{|c|}{ 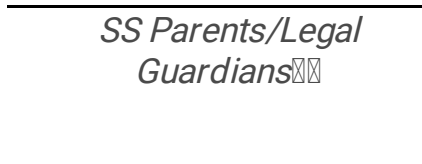 }} & \multicolumn{14}{|c|}{ RECOMMENDED LEVELS OF MVPA IN ADOLESCENT BOYS (60 minutes/day) } \\
\hline & & \multirow[b]{2}{*}{$\mathrm{n}$} & \multicolumn{4}{|c|}{ Unadjusted } & \multicolumn{3}{|c|}{ Adjusted $\rrbracket$} & \multicolumn{3}{|c|}{ Interaction ${ }^{\mathrm{a}}$} & \multicolumn{3}{|c|}{ Interaction ${ }^{b}$} \\
\hline & & & $\%$ & OR & $\mathrm{Cl}_{95 \%}$ & $\mathrm{p}$ & OR & $\mathrm{Cl}_{95 \%}$ & p & OR & $\mathrm{Cl}_{95 \%}$ & $\mathrm{p}$ & OR & $\mathrm{Cl}_{95 \%}$ & $\mathrm{p}$ \\
\hline \multirow[t]{3}{*}{ Encourage } & Never & 104 & 37.5 & 1 & & & & & & & & & & & \\
\hline & Sometimes & 313 & 40.3 & 1.40 & $\begin{array}{l}0.74- \\
2.62\end{array}$ & 0.305 & & & & & & & & & \\
\hline & Always & 145 & 43.0 & 1.35 & $\begin{array}{l}0.84- \\
2.16\end{array}$ & 0.215 & & & & & & & & & \\
\hline \multirow{3}{*}{$\begin{array}{l}\text { Pratice } \\
\text { togheter }\end{array}$} & Never & 205 & 37.4 & 1 & & & & & & & & & & & \\
\hline & Sometimes & 288 & 42.0 & 0.82 & $\begin{array}{r}0.40- \\
1.66\end{array}$ & 0.577 & & & & & & & & & \\
\hline & Always & 69 & 44.2 & 0.85 & $\begin{array}{l}0.45- \\
1.60\end{array}$ & 0.613 & & & & & & & & & \\
\hline \multirow[t]{3}{*}{ Transport } & Never & 268 & 40.5 & 1 & & & & & & & & & & & \\
\hline & Sometimes & 176 & 40.1 & 0.86 & $\begin{array}{r}0.52- \\
1.44\end{array}$ & 0.570 & & & & & & & & & \\
\hline & Always & $\begin{array}{l}118 \\
118\end{array}$ & 40.8 & 1.37 & $\begin{array}{l}0.80- \\
2.33\end{array}$ & 0.247 & & & & & & & & & \\
\hline \multirow[t]{3}{*}{ Assist } & Never & 239 & 39.4 & 1 & & & 1 & & & & & & & & \\
\hline & Sometimes & 235 & 40.4 & 1.26 & $\begin{array}{l}0.66- \\
2.41\end{array}$ & 0.484 & 1.28 & $\begin{array}{l}0.71- \\
2.30\end{array}$ & 0.418 & & & & & & \\
\hline & Always & 88 & 43.3 & 1.90 & $\begin{array}{l}1.07- \\
3.39\end{array}$ & 0.029 & 1.96 & $\begin{array}{l}1.16- \\
3.32\end{array}$ & $0.012^{\star}$ & & & & & & \\
\hline \multirow{3}{*}{ Comment } & Never & 209 & 38.7 & 1 & & & 1 & & & & & & & & \\
\hline & Sometimes & 232 & 43.9 & 1.55 & $\begin{array}{l}0.84- \\
2.87\end{array}$ & 0.165 & 1.50 & $\begin{array}{l}0.85- \\
2.67\end{array}$ & 0.166 & & & & & & \\
\hline & Always & $\begin{array}{l}121 \\
121\end{array}$ & 37.6 & 0.73 & $\begin{array}{r}0.44- \\
1.20\end{array}$ & 0.218 & 0.78 & $\begin{array}{c}0.49- \\
1.27\end{array}$ & 0.328 & & & & & & \\
\hline \multirow{2}{*}{$\begin{array}{l}\text { MVPA Parents } \\
\text { (150 } \\
\text { minutes/week) }\end{array}$} & $\begin{array}{l}\text { It does } \\
\text { not } \\
\text { meet }\end{array}$ & 411 & 42.5 & 1 & & & 1 & & & 1 & & & 1 & & \\
\hline & $\begin{array}{l}\text { It } \\
\text { meets }\end{array}$ & $\begin{array}{l}151 \\
151\end{array}$ & 35.8 & 2,68 & $\begin{array}{r}1.69- \\
4.24\end{array}$ & 0.000 & 2.78 & $\begin{array}{l}1.76- \\
4.38\end{array}$ & $0.000 *$ & 4.20 & $\begin{array}{l}1.96- \\
9.02\end{array}$ & $0.000 *$ & 3.47 & $\begin{array}{l}1.73- \\
6.96\end{array}$ & $0.000 *$ \\
\hline
\end{tabular}

SS: Social Support; MVPA: moderate vigorous physical activity; $₫$ Adjusted by the enter criterion, the value of $p \leq 0.20$ for the entry of the variable in the adjusted model was adopted; Interaction ${ }^{\mathrm{a}}$ by main breadwinner's education level; Interaction ${ }^{\mathrm{b}}$ by socioeconomic status (SES). *Statistically significant for the test; $p<0,05 ; \mathbb{}$ (SS Parents/Legal Guardians: How often do your parents encourage 
you to practice PA (physical activity)? Do they practice PA with you? Do they transport you or provide transportation so that you can go to the place where you practice PA? Do they assist you in PA? Do they comment that you are doing your PA well?

Table 3. Association the social support and the level of physical activity of parents/legal guardians with regards to recommended MVPA levels in adolescent girls $(n=1390)$.

\begin{tabular}{|c|c|c|c|c|c|c|c|c|c|c|c|c|c|c|c|}
\hline \multirow{3}{*}{\multicolumn{2}{|c|}{$\begin{array}{l}\text { SS Parents/Legal } \\
\text { Guardians } ₫ \otimes\end{array}$}} & \multicolumn{14}{|c|}{ RECOMMENDED LEVELS OF MVPA IN ADOLESCENT GIRLS (60 minutes /day) } \\
\hline & & \multirow[b]{2}{*}{$n$} & \multicolumn{4}{|c|}{ Unadjusted } & \multicolumn{3}{|c|}{ 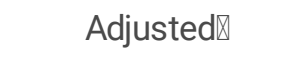 } & \multicolumn{3}{|c|}{ Interaction ${ }^{\mathrm{a}}$} & \multicolumn{3}{|c|}{ Interaction ${ }^{\mathrm{b}}$} \\
\hline & & & $\%$ & OR & $\mathrm{Cl}_{95 \%}$ & $\mathrm{p}$ & OR & $\mathrm{Cl}_{95 \%}$ & $\mathrm{p}$ & OR & $\mathrm{Cl}_{95 \%}$ & $\mathrm{p}$ & OR & $\mathrm{Cl}_{95 \%}$ & $\mathrm{p}$ \\
\hline \multirow[t]{3}{*}{ Encourage } & Never & 104 & 37.5 & 1 & & & 1 & & & & & & & & \\
\hline & Sometimes & 313 & 40.3 & 0.65 & $\begin{array}{r}0.38- \\
1.08\end{array}$ & 0.097 & 0.61 & $\begin{array}{l}0.37- \\
0.98\end{array}$ & $0.042^{\star}$ & & & & & & \\
\hline & Always & 145 & 43.0 & 1.01 & $\begin{array}{l}0.66- \\
1.55\end{array}$ & 0.966 & 1.06 & $\begin{array}{l}0.71- \\
1.59\end{array}$ & 0.771 & & & & & & \\
\hline \multirow{3}{*}{$\begin{array}{l}\text { Pratice } \\
\text { togheter }\end{array}$} & Never & 205 & 37.4 & 1 & & & & & & & & & & & \\
\hline & Sometimes & 288 & 42.0 & 1.33 & $\begin{array}{l}0.74- \\
2.38\end{array}$ & 0.883 & & & & & & & & & \\
\hline & Always & 69 & 44.2 & 1.39 & $\begin{array}{l}0.80- \\
2.40\end{array}$ & 0.685 & & & & & & & & & \\
\hline \multirow[t]{3}{*}{ Transport } & Never & 268 & 40.5 & 1 & & & & & & & & & & & \\
\hline & Sometimes & 176 & 40.1 & 0.78 & $\begin{array}{l}0.49- \\
1.25\end{array}$ & 0.301 & & & & & & & & & \\
\hline & Always & 118 & 40.8 & 1.07 & $\begin{array}{l}0.68- \\
1.69\end{array}$ & 0.774 & & & & & & & & & \\
\hline \multirow[t]{3}{*}{ Assist } & Never & 239 & 39.4 & 1 & & & & & & & & & & & \\
\hline & Sometimes & 235 & 40.4 & 0.97 & $\begin{array}{r}0.55- \\
1.68\end{array}$ & 0.892 & & & & & & & & & \\
\hline & Always & 88 & 43.3 & 1.08 & $\begin{array}{r}0.65- \\
1.80\end{array}$ & 0.758 & & & & & & & & & \\
\hline \multirow[t]{3}{*}{ Comment } & Never & 209 & 38.7 & 1 & & & 1 & & & & & & & & \\
\hline & Sometimes & 232 & 43.9 & 1.36 & $\begin{array}{r}0.84- \\
2.20\end{array}$ & 0.209 & 1.25 & $\begin{array}{l}0.82- \\
1.89\end{array}$ & 0.302 & & & & & & \\
\hline & Always & 121 & 37.6 & 1.41 & $\begin{array}{r}0.91- \\
2.18\end{array}$ & 0.127 & 1.46 & $\begin{array}{r}0.96- \\
2.23 \\
\end{array}$ & 0.075 & & & & & & \\
\hline \multirow[t]{2}{*}{$\begin{array}{l}\text { MVPA Parents } \\
\text { (150 } \\
\text { minutes/week) }\end{array}$} & $\begin{array}{l}\text { It does } \\
\text { not } \\
\text { meet }\end{array}$ & 411 & 42.5 & 1 & & & 1 & & & 1 & & & 1 & & \\
\hline & $\begin{array}{l}\text { It } \\
\text { meets }\end{array}$ & 151 & 35.8 & 1,99 & $\begin{array}{l}1.42- \\
2.80 \\
\end{array}$ & 0.000 & 2.04 & $\begin{array}{l}1.46- \\
2.87 \\
\end{array}$ & $0.000 *$ & 4.30 & $\begin{array}{l}2.41- \\
7.69 \\
\end{array}$ & $0.000 *$ & 2.11 & $\begin{array}{l}1.36- \\
3.29 \\
\end{array}$ & $0.001^{*}$ \\
\hline
\end{tabular}

SS: Social Support; MVPA: moderate vigorous physical activity; $₫$ Adjusted by the enter criterion, the value of $p \leq 0.20$ for the entry of the variable in the adjusted model was adopted; Interaction ${ }^{\mathrm{a}}$ by main breadwinner's education level; Interaction ${ }^{\mathrm{b}}$ by socioeconomic status (SES). *Statistically significant for the test; $\mathrm{p}<0.05$; $\mathbb{\square}$ SS Parents/Legal Guardians: How often do your parents encourage you to practice PA (physical activity)? Do they practice PA with you? Do they transport you or provide transportation so that you can go to the place where you practice PA? Do they assist you in PA? Do they comment that you are doing your PA well? 